\title{
DESIGN STRENGTH OF CONCRETE-FILLED STEEL COLUMNS
}

\author{
W.-H. Kang ${ }^{1, *}$, B. Uy ${ }^{2}$, Z. Tao ${ }^{1}$ and S. Hicks ${ }^{3}$ \\ ${ }^{1}$ Institute for Infrastructure Engineering, University of Western Sydney, Penrith, NSW 2751, Australia \\ ${ }^{2}$ Centre for Infrastructure Engineering \& Safety, The University of New South Wales, Sydney, NSW 2052, Australia \\ ${ }^{3}$ Heavy Engineering Research Association, Manukau, Auckland City, New Zealand \\ *(Corresponding author: E-mail: w.kang@uws.edu.au)
}

Received: 18 March 2013; Revised: 17 June 2014; Accepted: 24 June 2014

\begin{abstract}
The purpose of this paper is to recalibrate the capacity reduction factors, estimate the reliability of current equations, and investigate the effect of these factors in AS 5100.6, the Australian Bridge Standard for concrete-filled steel tubular columns. This work has important ramifications for other international codes of practice as the Australian code has the identical or similar underlying design philosophy with Eurocode 4, AISC and the code of practice in Hong Kong. The method developed by Johnson and Huang is extensively applied to the Australian code format to recalibrate the capacity factors in AS 5100 for a target reliability of $\beta=3.04$ based on an extensive database of 1,583 test results covering a wide range of input parameter values. In addition, an inverse analysis procedure based on Johnson and Huang's method is proposed to estimate the reliability of design equations with known capacity factors. The analysis results show that the interaction between the concrete and steel needs to be considered for the current capacity factors in AS 5100. The results also show that the current capacity factors provide greater reliability than the target reliability suggested in AS 5104:2005/ISO 2394:1998, but after considering the additional uncertainties created due to the application of multiple capacity factors, the reliability was almost the same as the recommended value. In conclusion, the current capacity factor values in AS 5100 are adequate with regards to safety and can be maintained, but better optimised values would be preferable to improve the cost-safety balance.
\end{abstract}

Keywords: Capacity factors, Composite structures, Concrete-filled steel columns, Design strength, Safety factor calibration

\section{INTRODUCTION}

Concrete-filled steel tubular (CFST) members have been used in many structural applications including high-rise buildings, bridges, and offshore structures, due to their outstanding mechanical performance: such as high axial load capacity, good ductility performance, large energy absorption capacity, and low strength degradation [1],[2]. In the structural design of these composite members, it is desirable to achieve the most optimised balance between the cost and the safety of the members in the context of the safety of the whole structure. The safety factors regarding the ultimate structural member resistance in the existing design code provisions need to be promptly checked as more experimental data becomes available and improved statistical techniques are developed. In addition, these factors should be determined based on the statistical rationale provided by a reliability analysis. In this context, this paper aims to recalibrate the capacity factors for the design of CFST members, to estimate the reliability of the current bridge design Standard in AS 5100 [3] and to investigate the optimal cost-safety balance of the current design codes. The proposed work in this paper has important ramifications for other international codes of practice as the Australian code has the identical or similar underlying design philosophy with Eurocode 4 (EC 4) [4], AISC [5], and the code of practice in Hong Kong [6]. 
In this paper, first a brief summary of the current code provisions of AS 5100: Australian Standard for Bridges for CFST columns is provided, and the database employed for the reliability based capacity recalibration analysis is introduced. An extensive database of failure tests of CFST members developed by Tao et al. [7] is used, which merged two available test databases established by Goode [8] and $\mathrm{Wu}$ [9]. Although this database includes the test results of six structural CFST member types (circular and rectangular columns, beam-columns, and beams) with a total of 2,194 test results, we herein limit our attention to CFST columns and use a total of 1,583 test results. Although more experimental studies have recently been carried on the axial load bearing capacity of CFST columns such as Gupta et. al. [10], Lue et al. [11], Tao et al. [12], Yu et al. [13], Yang and Han [14], and Chang et al. [15], they are not considered in this study as the number of test results in the Tao et al.'s database is already statistically sufficient. Based on this information, we conduct the following three types of reliability-based analyses: firstly, we recalibrate the capacity factors in AS 5100 using the statistical method proposed by Johnson and Huang [16]. This method is selected because: it can calibrate multiple factors at once; it assumes a lognormal distribution which is realistic for member strength with non-negative values; and it utilises the data only for member resistance, neglecting the load effect and its uncertainties. Secondly, we estimate the reliability of the design equations in AS 5100 with the existing specified capacity factors ( 0.9 for steel and 0.6 for concrete), by proposing a calculation procedure that is inverse of the method proposed by Johnson and Huang. Thirdly, the reliability estimation for the design codes and the capacity factors in AS 5100 is repeated, considering the effect of the applied capacity factors on the accuracy of the equations. Based on these calibration and reliability estimation results, discussions and recommendations are provided regarding useful in-sights into and supporting information for the current design code provisions.

\section{AUSTRALIAN CODE PROVISIONS FOR CFST MEMBERS}

\subsection{Ultimate Section Capacity}

In the Australian bridge standard, AS 5100 [3], the ultimate section capacity $\left(N_{\text {us }}\right)$ for a rectangular CFST stub column under axial compression is calculated as follows:

$$
N_{u s}=\phi A_{s} f_{y}+\phi_{c} A_{c} f_{c}^{\prime}
$$

where $A_{s}$ and $A_{c}=$ the areas of the steel and concrete sections, respectively; $f_{y}=$ the nominal yield strength of the steel; $f^{\prime}{ }_{c}=$ the characteristic compressive strength of the concrete; and $\phi$ and $\phi_{c}=$ the capacity reduction factors for steel and concrete, respectively (with the existing values given as 0.9 and 0.6). In this equation, the contribution of the reinforcement is not considered, because no test data in this study included this variable.

Eq. 1 can also be used for a circular CFST stub column. However, if the relative slenderness $\left(\lambda_{r}\right)$ is not greater than 0.5 and the eccentricity of loading under the greatest design bending moment is not greater than $d_{o} / 10$ (where $d_{o}$ is the diameter of a circular section), the additional increase in concrete strength due to the confinement effect should be considered. When the confinement effect is considered, the ultimate section capacity is as follows:

$$
N_{u s}=\phi A_{s} \eta_{2} f_{y}+\phi_{c} A_{c} f_{c}^{\prime}\left(1+\frac{\eta_{1} t f_{y}}{d_{o} f_{c}^{\prime}}\right)
$$

where $\eta_{1}$ and $\eta_{2}=$ the coefficients for reflecting the confinement effect. $\eta_{1}$ represents the concrete strength increase, and $\eta_{2}$ represents the steel strength reduction, due to the confinement effect. The calculation procedure for these coefficients is given in Clause 10.6.2.2 of AS 5100. 6 [3]. 


\subsection{Ultimate Member Capacity}

To estimate the ultimate member capacity $\left(N_{u c}\right)$, a slenderness effect represented by a slenderness reduction factor, $\alpha_{c}$, should be considered. For a stub column defined by $L_{e} / d_{o}$ or $L_{e} / b \leq 4$ (where $L_{e}=$ the effective length of a column, and $b=$ the section width of a rectangular tube), this slenderness effect can be ignored. Considering this slenderness reduction factor, the ultimate member capacity of a CFST column is calculated as follows:

$N_{u c}=\alpha_{c} N_{u s} \leq N_{u s}$

where $N_{u s}$ is calculated either from Eq. 1 or 2 . The slenderness reduction factor, $\alpha_{c}$, is calculated using the following equation:

$$
\alpha_{c}=\xi\left[1-\sqrt{1-\left(\frac{90}{\xi \lambda}\right)^{2}}\right]
$$

where $\xi$ is the compression member factor and $\lambda$ is a factor defined as a function of the relative slenderness $\left(\lambda_{r}\right) . \lambda_{r}$ is defined by $\sqrt{N_{u s} / N_{c r}}$, where $N_{u s}$ is calculated from either Eq. (1) or (2) but the capacity factors $\phi$ and $\phi_{c}$ are taken as unity; $N_{c r}$ is calculated as follows:

$$
\begin{aligned}
& N_{c r}=\frac{\pi^{2}(E I)_{e}}{L_{e}^{2}} \\
& (E I)_{e}=\phi E I_{s}+\phi_{c} E_{c} I_{c}
\end{aligned}
$$

where $I_{s}$ and $I_{c}$ are the second moment of the areas of the steel sections and uncracked concrete sections, respectively, and $\phi$ and $\phi_{c}$ are the capacity factors.

In this paper, we aim to calibrate the capacity reduction factors $\phi$ and $\phi_{c}$ in Eqs. 1 and 2 and investigate their effect on the reliability of the design equations, based on the extensive database developed by Tao et al. [7], introduced in the following section.

\section{DATABASE FOR CFST STUB COLUMNS}

Safety factors in the existing design code provisions may not provide the most optimal balance between cost and safety if they were developed based only on a limited number of test results. In this case, the factors need to be updated based on the latest collection from a database with a sufficient number of test results covering a wide range of input parameter values. For this purpose, we use the extensive database developed by Tao et al. [7], which covers the test results over the last few decades by merging two available test databases established by Goode [8] and Wu [9]. Goode's database contains 1,792 test results from 92 references, and Wu's database contains 1,514 test results from 104 references. In Tao et al.'s database, 1,575 test results from Goode's database were included (918 for circular members and 657 for rectangular members), discarding irrelevant datasets, and 619 test results from Wu's database were included that had not been included in Goode's database. A total of 2,194 test results (1,232 for circular members and 962 for rectangular members) from 130 references are included in Tao et al.'s database. In this paper, we limit our attention to column members and use a reduced database with 1,583 test results (445 for rectangular stub columns, 234 for long rectangular columns, 484 for circular stub columns, and 420 for circular long columns). Here, a stub column is defined as a short column member with $L_{e} / d_{o} \leq 4$ (for circular members) or $L_{e} / b \leq 4$ (for rectangular members), where $L_{e}$ is the effective length of a 
column, $d_{o}$ is the diameter of a circular section, and $b$ is the section width of a rectangular section. For a stub column, the slenderness effect is not considered.

In Tao et al.'s database, some references do not provide the mean measured compressive strength of concrete $\left(f_{c m}\right)$ values. They report the compressive strength values of $150 \mathrm{~mm}$ cubes $\left(f_{c u}\right)$ instead. In this case, the conversion table given by $\mathrm{Yu}$ et al. [17] representing the approximate relationship between cylinder strength $\left(f_{c m}\right)$ and cube strength $\left(f_{c u}\right)$ was used to obtain the equivalent compressive strength. This table was developed based on Chen et al.'s work [18], which determined the equivalent compressive strength of high-strength concrete.

Figure 1 shows an overview of the distributions of the key parameters in Tao et al.'s [7] database: the diameters $\left(d_{o}\right)$ or the longer side lengths $(B)$ of the steel tubes, the tube thicknesses $(t)$, the mean measured yield strength of the steel $\left(f_{y m}\right)$, the mean measured compressive strength of the concrete $\left(f_{c m}\right)$, the column lengths for long columns, and the width-to-thickness ratio or diameter-to-thickness ratio with the effect of yield strength $\left((B / t) / \sqrt{ }\left(250 / f_{y}\right)\right)$ or $\left((D / t) /\left(250 / f_{y}\right)\right)$. In this figure, the parameter ranges for the four section/member types (rectangular stub columns, circular stub columns, long rectangular columns, and long circular columns) are separately presented in Figures 1 (a), (b), (c), and (d).

In Figure 1 (a), for rectangular stub columns, most members have longer side lengths between 100 and $200 \mathrm{~mm}$, while some members have values outside of this range. Note that the longer to shorter side length ratio $\left(B / B_{\text {short }}\right)$ is between 1.00 and 2.00 . The thickness is mostly distributed between 1.47 and $8 \mathrm{~mm}$, while some members have values outside of this range. The mean measured yield strength of the steel $\left(f_{y m}\right)$ is uniformly distributed between 192 and $400 \mathrm{MPa}\left(\mathrm{N} / \mathrm{mm}^{2}\right)$, while a few members' yield strengths is $835 \mathrm{MPa}\left(\mathrm{N} / \mathrm{mm}^{2}\right)$. The mean measured compressive strength of the concrete $\left(f_{c m}\right)$ is almost uniformly distributed between 12 and $103 \mathrm{MPa}\left(\mathrm{N} / \mathrm{mm}^{2}\right)$. The width-to-thickness ratio with the effect of yield strength $\left((B / t) / \sqrt{ }\left(250 / f_{y}\right)\right)$ is mostly distributed between 12 and 100, while some members' values are outside of this range.

For circular stub columns, a similar distribution is observed in Figure 1 (b). Most members have diameters between 100 and $200 \mathrm{~mm}$, while several members have diameters up to $1,020 \mathrm{~mm}$. The thickness is mostly distributed between 0.52 and $8 \mathrm{~mm}$, while some members have values outside of this range. The mean measured yield strength of the steel $\left(f_{y m}\right)$ is uniformly distributed between 186 and $400 \mathrm{MPa}\left(\mathrm{N} / \mathrm{mm}^{2}\right)$, while a few members have a yield strength of $853 \mathrm{MPa}\left(\mathrm{N} / \mathrm{mm}^{2}\right)$. The mean measured compressive strength of the concrete $\left(f_{\mathrm{cm}}\right)$ is uniformly distributed between 10 and $110 \mathrm{MPa}\left(\mathrm{N} / \mathrm{mm}^{2}\right)$. The diameter-to-thickness ratio with the effect of yield strength $\left((D / t) /\left(250 / f_{y}\right)\right)$ is mostly distributed between 12 and 150, but still many members' have their values between 150 and 223.

For long rectangular columns, as shown in Figure 1 (c), most members have longer side lengths between 100 and $200 \mathrm{~mm}$. Note that the longer to shorter side length ratio $\left(B / B_{\text {short }}\right)$ is between 1.00 and 2.02. The thickness ranges between 1.5 and $6 \mathrm{~mm}$, while some members have values outside of this range. The mean measured yield strength of the steel $\left(f_{y m}\right)$ is uniformly distributed between 217 and $500 \mathrm{MPa}\left(\mathrm{N} / \mathrm{mm}^{2}\right)$, while a few members' yield strength is $550 \mathrm{MPa}\left(\mathrm{N} / \mathrm{mm}^{2}\right)$. The mean measured compressive strength of the concrete $\left(f_{\mathrm{cm}}\right)$ is almost uniformly distributed between 10 and $94 \mathrm{MPa}\left(\mathrm{N} / \mathrm{mm}^{2}\right)$. The length of the columns is also uniformly distributed between 482 and 4,000 $\mathrm{mm}$, while some members' column lengths are up to $4,494 \mathrm{~mm}$. The width-to-thickness ratio with the effect of yield strength $\left((B / t) / \sqrt{ }\left(250 / f_{y}\right)\right)$ is mostly distributed between 18 and 100, and only few members' values are outside of this range. 


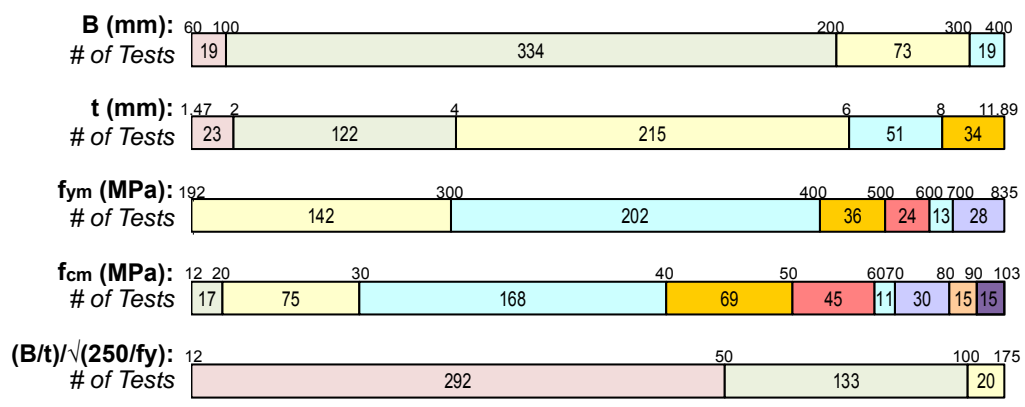

(a) Rectangular stub columns

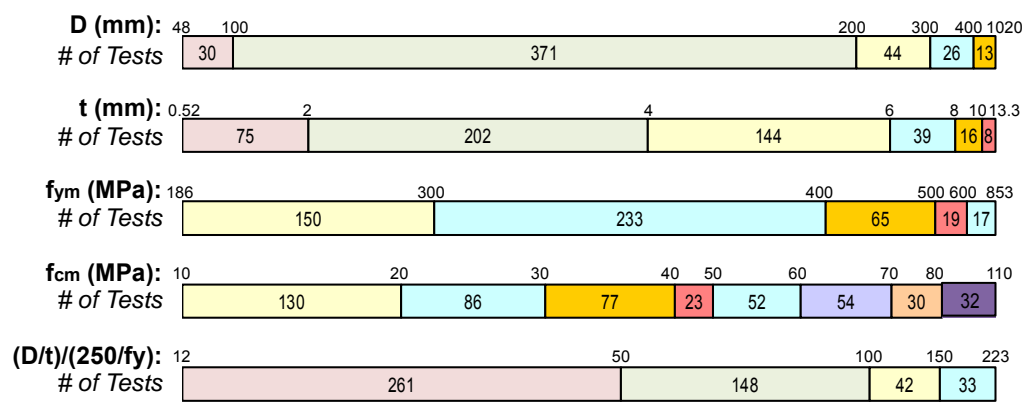

(b) Circular stub columns

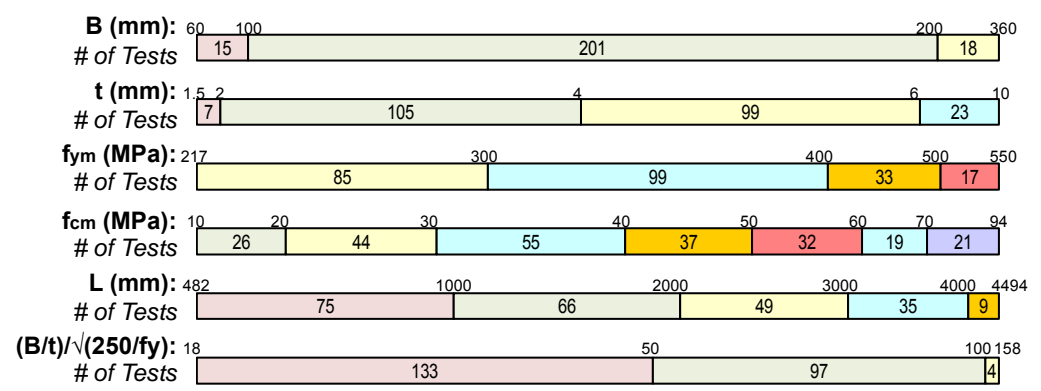

\section{(c) Long rectangular columns}

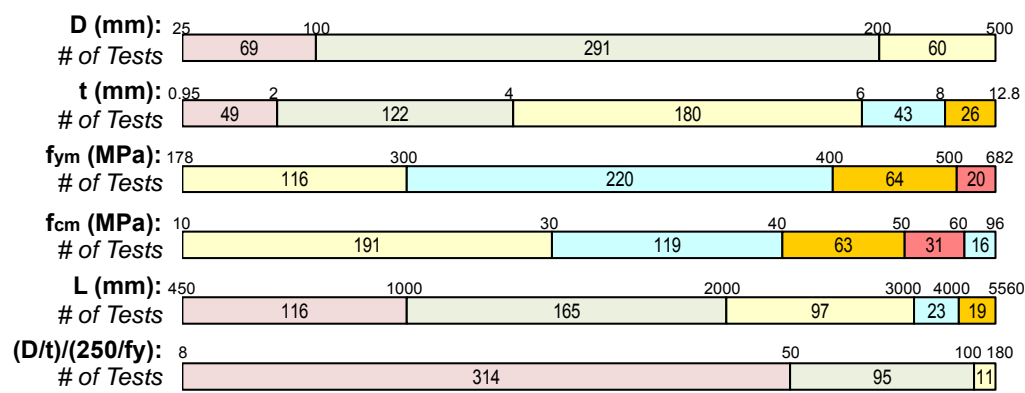

\section{(d) Long circular columns}

Figure 1. Distribution of Parameter Values in Tao et al.'s Database [7] 
For long circular columns, as shown in Figure 1 (d), most members have longer side lengths between 100 and $200 \mathrm{~mm}$, and the thickness ranging between 0.95 and $8 \mathrm{~mm}$, while some members have values outside of this range. The mean measured yield strength of the steel $\left(f_{y m}\right)$ is uniformly distributed between 178 and $500 \mathrm{MPa}\left(\mathrm{N} / \mathrm{mm}^{2}\right)$, while a few members' yield strength is $682 \mathrm{MPa}$ $\left(\mathrm{N} / \mathrm{mm}^{2}\right)$. The mean measured compressive strength of the concrete $\left(f_{c m}\right)$ is almost uniformly distributed between 10 and $96 \mathrm{MPa}\left(\mathrm{N} / \mathrm{mm}^{2}\right)$. The length of the columns is also uniformly distributed between 450 and 4,000 mm, while some members' column length is up to 5,560 mm. The diameter-to-thickness ratio with the effect of yield strength $\left((D / t) /\left(250 / f_{y}\right)\right)$ is mostly distributed between 8 and 100, and some values are outside of this range.

Because the experiments were conducted for research purposes, some cases may not represent the realistic conditions of existing structures. However, the comprehensiveness of the database enables us to cover a wide range of parameter values. The database lacks uniformity regarding some of the key parameters because it was randomly assembled from numerous test results in the literature. This should be carefully considered when the capacity factor calibration and reliability analysis results are used.

\section{CAPACITY FACTOR CALIBRATION METHOD}

Based on the extensive database introduced in the previous section, we first adopt the statistical method proposed by Johnson and Huang [16] to calibrate the capacity factors in the resistance functions of CFST stub column members in AS 5100 [3]. Although this method was originally developed for the calibration of the partial safety factors of short and slender concrete-encased composite columns under combined axial compression and uni-axial bending, this method can be extensively applied to the calibration of the partial safety factors or capacity factors of any resistance function with multiple factors. In this study, this method is selected for the following three reasons: 1) This method can calibrate multiple capacity factors at the same time, which is required for the calibration of the two capacity factors for steel and concrete in CFST columns. 2) This method assumes that the CFST columns' strength follows a lognormal distribution with the lower limit at zero, instead of a normal distribution, and this corresponds to reality [19]. 3) This method considers the resistance of the CFST columns and neglects the load effect by using the First Order Reliability Method (FORM) sensitivity factor for resistance. Therefore, we can fully utilise the database introduced in the previous section, which does not have information about loading uncertainties. In this section, a summary of Johnson and Huang's method is provided. It includes a modification to allow its application to the Australian design code format, which has capacity factors $\phi$ instead of partial safety factors $2 \mathrm{M}$ (where $\phi=1 / 2 \mathrm{M}$ ).

\subsection{Capacity Factor Calibration Method}

Let $g_{R}(\mathbf{x})$ be a resistance function in an existing code provision, where $\mathbf{x}$ is a vector of the input parameters. In this study, $g_{R}(\mathbf{x})=$ the resistance functions in Eqs. 1 and 2 , and $\mathbf{x}=\left\{f_{y}, f^{\prime}{ }^{\prime}, d_{o}, B, L\right.$, $\ldots\}$, where the values of $f_{y}$ and $f^{\prime}{ }_{c}$ are taken as those of $f_{y m}$ and $f_{c m}$ (mean-measured values).

The first step in capacity factor calibration is to make the resistance function unbiased. All the capacity factors inside the function are taken to be unity, and the intrinsic bias is corrected using the following bias correction term:

$\bar{b}=\frac{1}{N} \sum_{i=1}^{N}\left(\frac{r_{e i}}{r_{t i}}\right)$ 
where $N=$ the number of test results in the database, e.g., in this study, $N=445,234,484$, and 420 for rectangular stub columns, long rectangular columns, circular stub columns, and long circular columns, respectively; $r_{e i}=$ the experimental resistance observed from the $i$-th test result; and $r_{t i}=$ the theoretical resistance calculated from $g_{R}\left(\mathbf{x}_{\mathrm{i}}\right)$, where $\mathbf{x}_{\mathrm{i}}$ is a set of mean-measured input parameters used in the $i$-th test. The intrinsic bias exists because the resistance function was not calibrated based on an extensive database. By multiplying this bias correction term with the resistance function, we can predict the unbiased resistance of $g_{R}(\mathbf{x})$ as follows:

$r=\bar{b} g_{R}(\mathbf{x}) \delta$

where $r=$ a predicted resistance for a given set of $\mathbf{x}$ after bias correction and $\delta$ is the error of the unbiased resistance function. The error term for each test result, $\delta_{i}$, is estimated as follows:

$\delta_{i}=\frac{r_{e i}}{\bar{b} r_{t i}}$

where $\quad r_{e i}=$ the experimental resistance observed from the $i$-th test result and $r_{t i}=$ the theoretical resistance obtained from $g_{R}\left(\mathbf{x}_{\mathbf{i}}\right)$ using the mean measured input parameters. This error term represents the modelling uncertainty of the unbiased prediction model from all possible sources for prediction errors such as oversimplification in the design equations and the neglect of the size effect.

The variance of $r$ in Eq. 8 is obtained from two sources: 1) the variance of the error term $(\delta)$ in Eq. 8 , and 2) the variance of the resistance function $g_{R}(\mathbf{x})$ based on the uncertainties in the input parameters $\mathbf{x}$. Assuming that $r$ in Eq. 8 follows a lognormal distribution, the coefficient of variation of $r$ in Eq. 8 is estimated as follows:

$V_{r} \cong \sqrt{\left(V_{\delta}^{2}+V_{r t}^{2}\right)}$

where $V_{\delta}=$ the coefficient of variation of the error term $(\delta)$; and $V_{r t}=$ the coefficient of variation of $g_{R}(\mathbf{x})$ due to the uncertainties in the input parameters $\mathbf{x}$. $V_{\delta}$ can be statistically estimated from $\delta_{i}$ $(i=1, \ldots, N)$ in Eq. 9, and $V_{r t}$ can be estimated for each test result using a Monte Carlo simulation or the first-order approximation of moments [20]. To calculate $V_{r t}$, we assume that the mean values of the input parameters $\mathbf{x}$ are taken as the mean measured values in each test, and the coefficient of variation of the input parameters is obtained from Table 1 . Note that the coefficient of variation (c.o.v.) of $f^{\prime}{ }_{c}$ is not directly provided by AS 3600/ NZS 3104 [22],[23], but the values of $f_{c m}$ according to those of $f^{\prime} c$ are provided. Therefore, the c.o.v. of $f^{\prime} c$ was inferred from the definition that $f^{\prime}{ }_{c}$ is the lower $5 \%$ fractile of $f_{c m}$. The value for $f_{c m}$ was chosen as the average of the $f_{c m}$ values for the entire test dataset.

Table 1. Coefficient of Variation (c.o.v.) of Basic Variables

\begin{tabular}{lll}
\hline Variables & c.o.v. & References \\
\hline Yield strength of steel $\left(f_{y}\right)$ & 0.07 & {$[21]$} \\
Compressive strength of concrete $\left(f^{\prime}{ }^{\prime}\right)$ & 0.10 & {$[22],[23]$} \\
All linear dimensions $\left(d_{o}, b\right.$, and $\left.L\right)$ & 0.01 & {$[3],[24]$} \\
Tube thickness $(t)$ & 0.10 & {$[24]$} \\
\hline
\end{tabular}

Because we assume that $r$ in Eq. 8 follows a lognormal distribution, the standard deviation of $\ln r$ $(\sigma \ln r)$ is calculated as follows:

$\sigma_{\ln r}=\sqrt{\ln \left(1+V_{r}^{2}\right)}$ 
This standard deviation is used to calculate the target design value of the resistance $\left(r_{d}\right)$ for a target reliability index $\beta$ as follows:

$r_{d}=\bar{b} g_{R}(\mathbf{x}) \exp \left(-k \sigma_{\ln r}-0.5 \sigma_{\ln r}^{2}\right)$

where

$k=\frac{\left(k_{d} V_{\delta}^{2}+\beta V_{r t}^{2}\right)}{V_{r}^{2}}$

and $k_{d}=$ the fractile factor corresponding to $\beta$ at the $75 \%$ confidence level, determined for a number of test data $N$ from a non-central $t$-distribution. Note that the target reliability index $\beta$ considers only the resistance, and ignores the effect of loads. In this case, AS 5104: 2005/ISO 2394:1998

[26],[27] recommends that $\beta$ be empirically estimated as $\alpha_{R} \times \beta_{t}$, where $\beta_{t}=$ the target reliability considering both resistance and load effects and $\alpha_{\mathrm{R}}=$ the First Order Reliability Method (FORM) sensitivity factor when resistance is taken as 0.8 . Therefore, the design value for resistance corresponds to the product $\alpha_{R} \beta=0.8 \times 3.8=3.04$ (equivalent to the probability of the actual resistance falling below the design resistance of 1 in $845=0.0012)$.

\subsection{Determination of Capacity Factors}

This section provides the calculation steps of the statistical method proposed by Johnson and Huang [16] to estimate the multiple capacity factors for steel $(\phi)$ and concrete $\left(\phi_{c}\right)$. We assume that these capacity factors are defined by the product of a material independent model factor $\left(\phi_{m}\right)$, and material dependent factors $\phi_{m s}$ for steel and $\phi_{m c}$ for concrete. In other words, $\phi=\phi_{m} \times \phi_{m s}$ for steel, and $\phi_{c}=\phi_{m} \times \phi_{m c}$ for concrete.

First, we calculate the material dependent factors $\left(\phi_{m s}\right.$ and $\left.\phi_{m c}\right)$ by using the ratio between the characteristic strength and the design strength of each material. For example, the characteristic strength of structural steel is defined as follows:

$f_{y k}=\bar{f}_{y} \exp \left(-1.64 \sigma_{\ln f_{y}}-0.5 \sigma_{\ln f_{y}}^{2}\right)$

where

$\sigma_{\ln f_{y}}=\sqrt{\ln \left(1+V_{f_{y}}^{2}\right)}$

and $V_{f_{y}}=0.07$ from Table 1 . The design strength of steel for the target reliability index $\beta$ is defined as follows:

$f_{y d}=\bar{f}_{y} \exp \left(-\beta \sigma_{\ln f_{y}}-0.5 \sigma_{\ln f_{y}}^{2}\right)$

Then, the material dependent factor for steel, $\phi_{m s}$, is obtained from the ratio of Eqs. 15 and 16 as follows:

$\phi_{m s}=\frac{f_{y d}}{f_{y k}}=\frac{1}{\exp \left[(\beta-1.64) \sigma_{\ln f_{y}}\right]}$

The calculations in Eqs. 14-17 are repeated for concrete to calculate the material dependent factor $\phi_{m c}$, by replacing $V_{f_{y}}$ with $V_{f_{c}}=0.015$, as suggested in Table 1 . 
Next, we calculate the material independent model factor $\left(\phi_{m}\right)$ for the $i$-th test result as follows:

$r_{d i}=g_{R}\left(\Theta_{i}, \mathbf{x}_{k i}, \mathbf{x}_{r i}\right)$

where $r_{d i}=$ the target design value obtained in Eq. 12 for each test result; $\Theta_{i}=$ the capacity reduction factors $\phi$ and $\phi_{c}$ for the $i$-th test; $\mathbf{x}_{k i}=$ the characteristic strength of the materials $\left(f_{y}\right.$ and $f_{c}$ ) for the $i$-th test; and $\mathbf{x}_{r i}=$ the input parameters, except $\mathbf{x}_{k i}$, for the $i$-th test. In this equation, for the $i$-th test, the only unknown term is the material independent factor $\phi_{m i}$ inside $\Theta_{i}$. This term can easily be obtained using any numerical solver for non-linear programming. In this study, the Active-Set Optimisation algorithm [29] is used. We repeat this calculation for the entire test dataset and find the material dependent factor, $\phi_{m}$ by averaging $\phi_{m i}$ as follows:

$\phi_{m}=\frac{1}{N} \sum_{i=1}^{N} \phi_{m i}$

Finally, the capacity factors are calculated as follows:

$\phi=\phi_{m} \times \phi_{m s}$ (for steel) and $\phi_{c}=\phi_{m} \times \phi_{m c}$ (for concrete)

\section{INVERSE ANALYSIS METHOD FOR THE RELIABILITY ESTIMATION OF EXISTING DESIGN EQUATIONS}

In this section, an approach that is the inverse of the Johnson and Huang's method [16] for estimating the reliability of existing design codes for given capacity factors is proposed. It can be used when the capacity factors are known but the corresponding reliability index is unknown. This inverse approach is useful in quantifying the conservatism of the design equations with given capacity factors in terms of reliability.

This approach is based on inverting Johnson and Huang's method, which was introduced in the previous section. Let $g_{R}\left(\Theta, \mathbf{x}_{k}, \mathbf{x}_{r}\right)$ be a resistance function, where $\mathbf{x}_{k}=$ the characteristic strength of the materials; $\mathbf{x}_{r}=$ the input parameters, except $\mathbf{x}_{k}$; and $\Theta=$ the capacity factors which are given. To calculate the reliability index of an equation with known capacity factors, the following equation can be derived by combining Eqs. 12 and 18 for each test datum:

$\bar{b} g_{R}\left(\mathbf{x}_{i}\right) \exp \left(-k \sigma_{\ln r}-0.5 \sigma_{\ln r}^{2}\right)=g_{R}\left(\mathbf{x}_{k i}, \mathbf{x}_{r i}, \Theta\right)$

where all the terms on the left-hand side $\left(\bar{b}, g_{R}\left(\mathbf{x}_{i}\right)\right.$, k, and $\left.\sigma_{\ln r}\right)$ can be calculated using Eqs. 7-13, except the target reliability index $\beta$ in Eq. 13, which is also included in $k_{d}$ in Eq. 13. This is the only unknown term in this equation, and it is calculated as $\beta_{i}$ for each test result. The right-hand side of Eq. 21 is the design resistance, which is calculated from the design equation with the given capacity factors. Eq. 21 can be solved numerically for the only unknown term $\beta$. Again, the Active-Set Optimisation algorithm [29] is used as a numerical solver for this nonlinear equation. This solving for the term $\beta_{i}$ in Eq. 21 is repeated for the complete test results, and the reliability of a design equation with given capacity factors is calculated as the average of the $\beta_{i}$ values as follows:

$\beta=\frac{1}{N} \sum_{i=1}^{N} \beta_{i}$

where $N=$ the number of test results. 


\section{RESULTS AND DISCUSSIONS}

\subsection{Capacity Factor Calibration using Johnson and Huang's Method}

In this section, we first use Johnson and Huang's method summarised in Section 4 to calibrate the capacity reduction factors $\left(\phi\right.$ and $\left.\phi_{c}\right)$ in Eqs. 1 and 2. The preliminary work of this analysis can be found in [25], in which Johnson and Huang's method was used to calibrate the factors for CFST stub columns according to the Eurocode format. For this calibration, we need to set the target reliability index $\beta$ required in Eqs. 13 and 17. The target reliability index is related to the expected social and economic consequences of a design failure. According to AS 5104: 2005 [26] /ISO 2394:1998 [27], the suggested reliability index for ultimate limit-state design is $\beta_{t}=3.8$, which corresponds to a case in which the consequences of failure are great (the highest level) and the relative costs of safety measures are moderate (Table 2). These are equivalent to 'Consequence Classes' in EN 1990, and 'Importance Levels' in AS/NZS 1170 [28]. As mentioned earlier, the procedure in Section 4 only considers resistance, ignoring the load effect, and the target reliability index $\beta$ is calculated as $0.8 \beta_{t}=3.04$ by using a dominating resistance parameter, $\alpha_{\mathrm{R}}=0.8$, as recommended in AS 5104: 2005 [26] /ISO 2394:1998 [27].

Based on this target reliability index, the calculations in Eqs. 7-20 are conducted, and the capacity reduction factors for steel and concrete for rectangular and circular columns are calculated. The results are reported in Table 3, along with the results of the intermediate steps.

Table 3. Results Summary for Target Reliability Index $\beta=3.04$

\begin{tabular}{cccccc}
\hline \multirow{2}{*}{ Section types } & Member types & $\begin{array}{c}\bar{b} \\
\text { Eq. (7) }\end{array}$ & $\begin{array}{c}V r \\
\text { (mean) } \\
\text { Eq. (10) }\end{array}$ & $\phi$ & $\phi_{c}$ \\
\hline \multirow{2}{*}{ Rectangular } & Stub columns & 1.06 & 0.14 & 0.82 & 0.77 \\
& Long columns & 1.10 & 0.16 & 0.82 & 0.76 \\
\hline \multirow{2}{*}{ Circular } & Stub columns & 1.03 & 0.15 & 0.78 & 0.73 \\
& Long columns & 1.11 & 0.16 & 0.83 & 0.77 \\
\hline
\end{tabular}

In this table, the constant bias term $\bar{b}$ refers to the conservatism embedded in a design equation calculated using Eq. 7, and the average of the coefficient of variation of the resistance function $V_{r}$ (mean) refers to the accuracy of a given design equation, considering the modelling and parameter uncertainties calculated using Eq. 10. Because $\bar{b}$ is defined in terms of the ratio between the experimental resistance and the theoretical resistance, if the $\bar{b}$ of a design equation is close to 1 , the equation has almost no conservatism. In other words, the greater the capacity factor values are, the more embedded conservatism there is. A large $V_{r}$ (mean) value indicates large uncertainties in a design equation. To achieve the same target reliability with a large value of $V_{r}$ (mean), the capacity factors should be decreased to achieve more conservatism.

From the results reported in the table, long rectangular columns require slightly smaller capacity factors than long circular columns because they have a slightly smaller $\bar{b}$ value with the same $V_{r}$ (mean) values. Similarly, circular stub columns require the smallest capacity factors because they have the lowest $\bar{b}$ value. The design equations for circular stub columns have almost no conservatism in itself as its $\bar{b}$ value is 1.03 , which is close to 1 .

Based on the results of this table, the overall calibrated capacity reduction factors show values for steel and concrete that are closer together than the values suggested in AS 5100, i.e., $\phi=0.9$, and $\phi_{c}$ $=0.6$. The capacity reduction factor of steel shows a reduction, but that of concrete shows increases 
for both rectangular and circular members. This difference can be explained by 1) the fact that the results in this paper were obtained based on an extensive up-to-date database with a large number of test results; and 2) the fact that the capacity reduction factors in AS 5100 were originally suggested for the separate use of steel and concrete, and they do not fully reflect the simultaneous behaviours of concrete and steel, such as the confinement effect of steel tubes. In Figure 2, the calibrated results of the capacity reduction factors in Eq. 20 are plotted for a range of target reliability values between 2.5 and 4.2 to demonstrate the sensitivity of the results. These plots show that the capacity reduction factors vary linearly according to the target reliability.

Based on these results, we cannot conclude that the current AS 5100 code should be immediately updated because we do not know how much conservatism is embedded in the capacity factors provided in AS 5100. However, the interaction between concrete and steel should be carefully considered when the capacity reduction factors are updated because the values of the capacity reduction factors are closer to one another than those in AS 5100 [3] for the overall range of reliability indices.

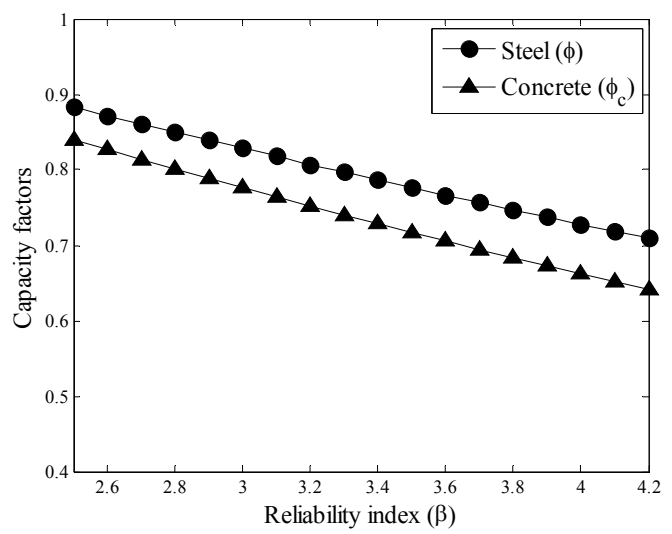

(a) Rectangular stub columns

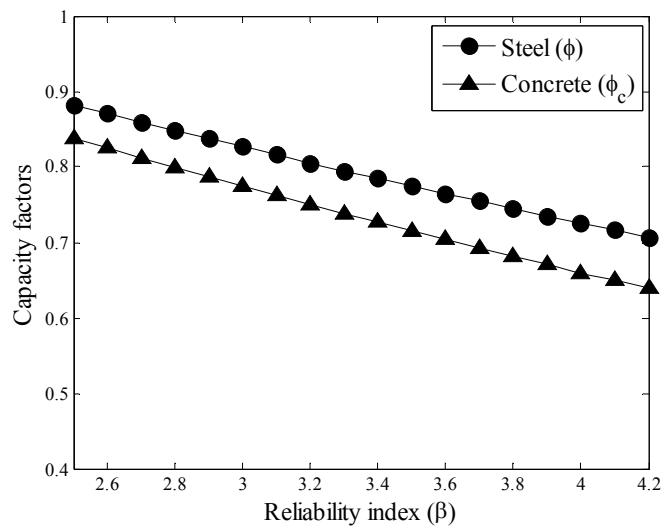

(c) Long rectangular columns

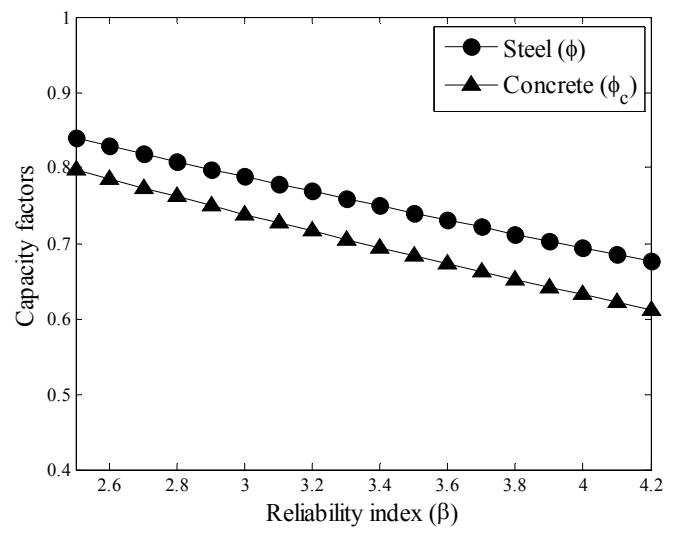

(b) Circular stub columns

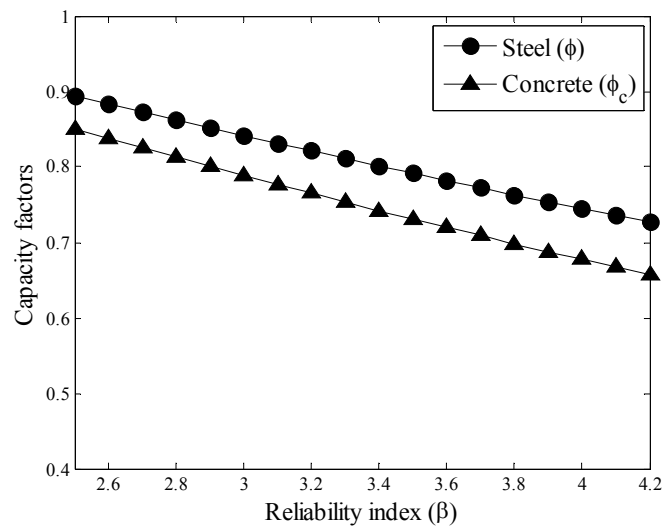

(d) Long circular columns

Figure 2. Capacity Factor Versus Reliability Index for Different Member Types 
To compare the effects of the capacity factor values calculated using Johnson and Huang's method [16] and those provided in AS 5100, regarding the design equations' reliability, the inverse analysis method proposed in Section 5 is utilised. For these two cases, inverse analyses have been performed, and the reliability for each section/member types has been calculated. The results are listed in Table 4. In this table, we can first confirm that, for all cases, the capacity factors obtained using Johnson and Huang's method provide reliability indices similar to the target reliability index, $\beta=3.04$, as expected, while the capacity factors given by AS 5100 provide much higher reliability indices that are close to 3.40. Here, the slight fluctuations in the values around 3.04 for the capacity factors calculated from Johnson and Huang's method are caused by the error produced by the numerical solvers and the averaging procedures in Eqs. 19 and 22, where the scattering of the calculated values is neglected. These results are also illustrated in Figure 3 as a bar graph. In this graph, the dotted lines show the reliability index $\beta=3.04$. Johnson and Huang's method's capacity factors provide reliability around this dotted line while the capacity factors provided in AS 5100 provide greater reliability around a value of 3.4, indicating greater conservatism. In addition, different section/member types of CFST columns provide different reliability indices based on type because the design equations themselves have different embedded conservatisms and accuracies for different column types.

The conservatism of the capacity factors provided by AS 5100 can also be clearly confirmed by the following analyses. Here, we calculate the optimal capacity factors for the target reliability index, $\beta$ $=3.04$, but we fix one of the capacity factors as the value provided in AS 5100 and calculate the other factor. For example, we fix the capacity factor for steel as 0.9 and calculate the remaining capacity factor for concrete, or we fix the capacity factor for concrete as 0.6 and calculate the remaining capacity factor for steel. From this analysis, we can confirm that the design equations are conservative if the calculated capacity factor has greater values than those in AS 5100 for the target reliability index, $\beta=3.04$, and vice versa. For these analyses, all the calculations in Eqs. 7-13 are used in a same manner, but the remaining calculation steps in Eqs. 14-20 are modified so as to be simpler because we only estimate a single capacity factor. The calculation steps and assumptions used in Eqs. 14-17 are not needed in this analysis, because they are only needed for multiple capacity factor calculation, and in Eq. 18, the unknown term $\phi_{m i}$ inside $\Theta_{i}$ is replaced by $\phi_{i}$ for steel or $\phi_{c i}$ for concrete for the $i$-th test. Again, to solve for $\phi_{i}$ or $\phi_{c i}$, any numerical solver designed for non-linear programming can be used, and in this study, the Active-Set Optimisation algorithm [29] is used.

Table 4. Calculated Reliability Indices from the Inverse Analysis

\begin{tabular}{cccc}
\hline Section types & Member types & Capacity factors & Reliability index $(\beta)$ \\
\hline \multirow{3}{*}{ Rectangular } & \multirow{2}{*}{ Stub columns } & Johnson and Huang, $\phi=0.82, \phi_{c}=0.77$ & 3.06 \\
& & AS 5100, $\phi=0.9, \phi_{c}=0.6$ & 3.43 \\
& \multirow{3}{*}{ Long columns } & Johnson and Huang, $\phi=0.82, \phi_{c}=0.76$ & 3.02 \\
& \multirow{3}{*}{ Stub columns } & AS 5100, $\phi=0.9, \phi_{c}=0.6$ & 3.44 \\
\hline \multirow{3}{*}{ Circular } & \multirow{2}{*}{ Johnson and Huang, $\phi=0.78, \phi_{c}=0.73$} & 2.97 \\
& \multirow{2}{*}{ Long columns } & AS 5100, $\phi=0.9, \phi_{c}=0.6$ & 3.49 \\
& & Johnson and Huang, $\phi=0.83, \phi_{c}=0.77$ & 3.00 \\
\hline
\end{tabular}

The analysis results are plotted in Figures 4 and 5, where one capacity factor is calculated for a 
range of target reliability values between 2.5 and 4.2 when the other factor is fixed to the value provided in AS 5100. Figure 4 shows the results when the capacity factor for steel is fixed at 0.9 and the factor for concrete is calculated. Figure 5 shows the results when the capacity factor for concrete is fixed at 0.6 and the factor for steel is calculated. For all results in Figure 4, the calculated capacity factor for concrete is always greater than 0.6 for the target reliability index, $\beta=$ 3.04. This means that the capacity factors given in AS 5100 provide higher reliability than the target reliability, implying more conservatism. This observation is also supported by Figure 5, and the calculated capacity factor for steel is always greater than that provided in AS 5100 for the target reliability index, $\beta=3.04$. These results are consistent with the inverse reliability analysis results in Table 4 and Figure 3.

Table 5. Conservatism and Uncertainties after applying Capacity Factors

\begin{tabular}{|c|c|c|c|c|c|}
\hline Section types & $\begin{array}{c}\text { Member } \\
\text { types }\end{array}$ & Capacity factors & $\begin{array}{c}\bar{b} \\
\text { Eq. (7) }\end{array}$ & $\begin{array}{c}V r \\
\text { (mean) } \\
\text { Eq. (10) } \\
\text { (before applying } \\
\text { capacity factors) }\end{array}$ & $\begin{array}{c}V r \\
(\text { mean) } \\
\text { Eq. }(10)\end{array}$ \\
\hline \multirow{4}{*}{ Rectangular } & \multirow{2}{*}{$\begin{array}{c}\text { Stub } \\
\text { columns }\end{array}$} & Johnson and Huang, $\phi=0.82, \phi_{c}=0.77$ & 1.33 & \multirow{2}{*}{0.14} & 0.14 \\
\hline & & AS 5100, $\phi=0.9, \phi_{c}=0.6$ & 1.40 & & 0.16 \\
\hline & \multirow{2}{*}{$\begin{array}{l}\text { Long } \\
\text { columns }\end{array}$} & Johnson and Huang, $\phi=0.82, \phi_{c}=0.76$ & 1.43 & \multirow{2}{*}{0.16} & 0.16 \\
\hline & & AS 5100, $\phi=0.9, \phi_{c}=0.6$ & 1.54 & & 0.18 \\
\hline \multirow{4}{*}{ Circular } & \multirow{2}{*}{$\begin{array}{c}\text { Stub } \\
\text { columns }\end{array}$} & Johnson and Huang, $\phi=0.78, \phi_{c}=0.73$ & 1.37 & \multirow{2}{*}{0.15} & 0.15 \\
\hline & & AS 5100, $\phi=0.9, \phi_{c}=0.6$ & 1.50 & & 0.15 \\
\hline & \multirow{2}{*}{$\begin{array}{l}\text { Long } \\
\text { columns }\end{array}$} & Johnson and Huang, $\phi=0.83, \phi_{c}=0.77$ & 1.46 & \multirow{2}{*}{0.16} & 0.18 \\
\hline & & AS $5100, \phi=0.9, \phi_{c}=0.6$ & 1.54 & & 0.18 \\
\hline
\end{tabular}

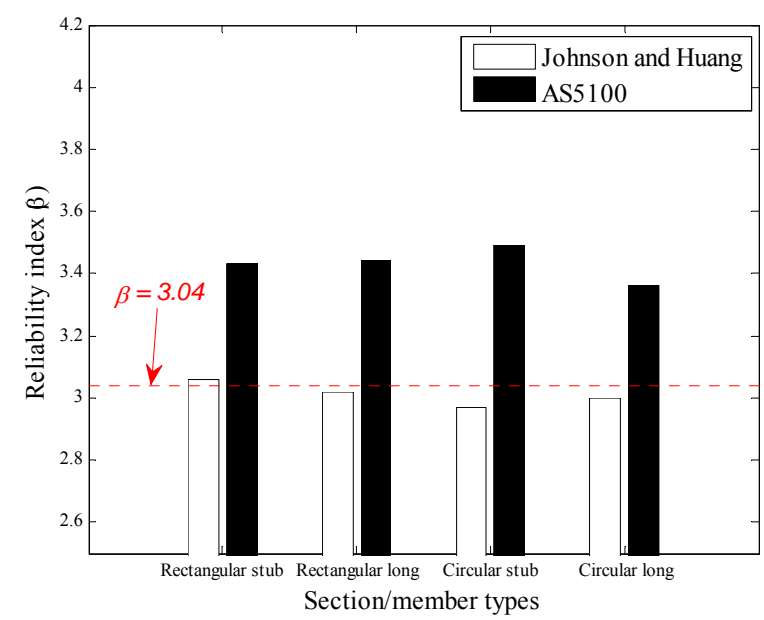

Figure 3. Comparison of Reliability Indices for Different Capacity Factors 
To see the conservatism of the capacity factors for both steel and concrete in AS 5100, similar analyses have been performed by fixing the capacity factor for steel at 0.93 , which is a slightly increased value from that in AS 5100. This value was chosen to confirm if the capacity factor for concrete is still greater than the value provided in AS 5100 when using this slightly increased value in the capacity factor for steel. The analysis results are plotted in Figure 6, and again, for all section/member types, the calculated capacity factor for concrete for the target reliability index, $\beta=$ 3.04 is still greater than 0.6, which is the value provided in AS 5100. These results imply that the capacity factors provided in AS 5100 are conservative compared to the target reliability suggesting both capacity factors can be slightly increased to create an optimal design.

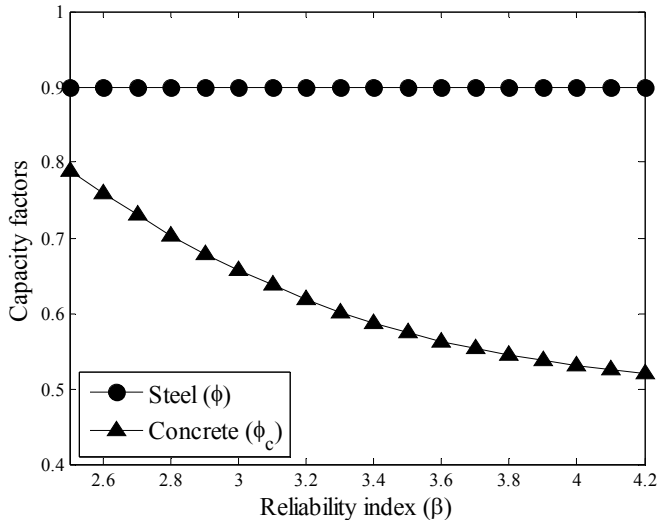

(a) Rectangular stub columns

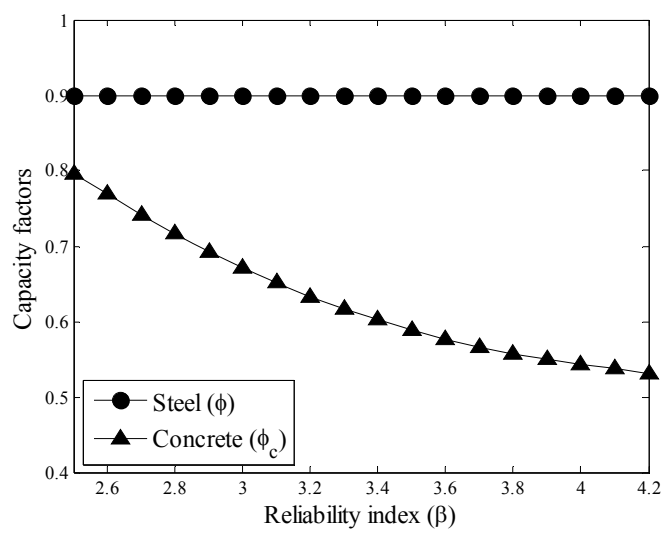

(c) Long rectangular columns

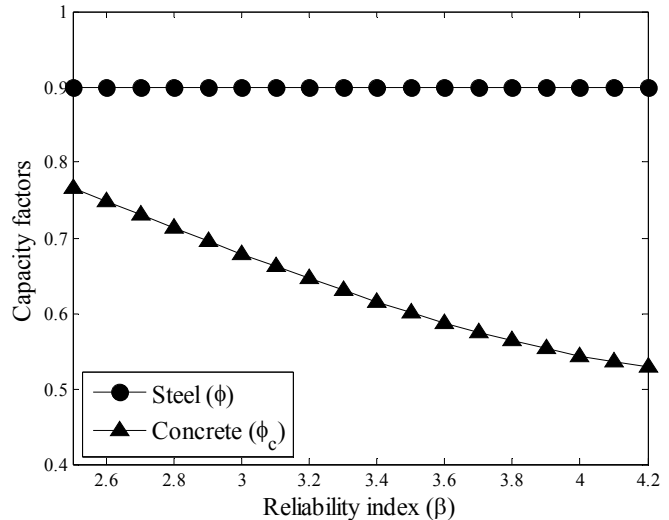

(b) Circular stub columns

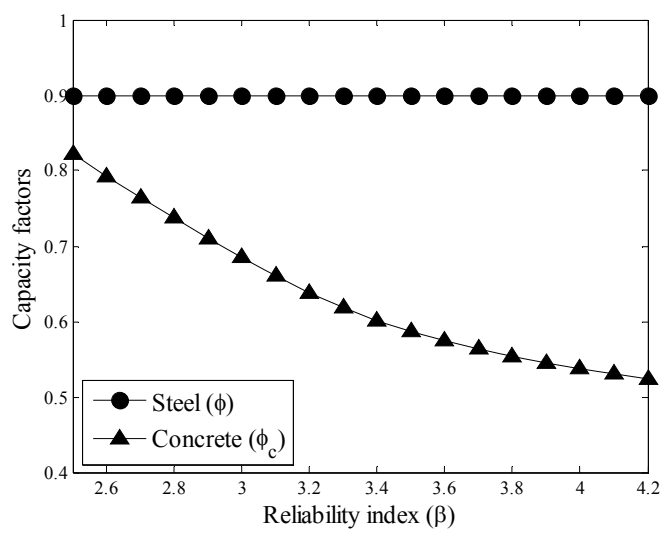

(d) Long circular columns

Figure 4. Capacity Factor Versus Reliability Index when the Capacity Factor for Steel is Fixed at 0.9. 


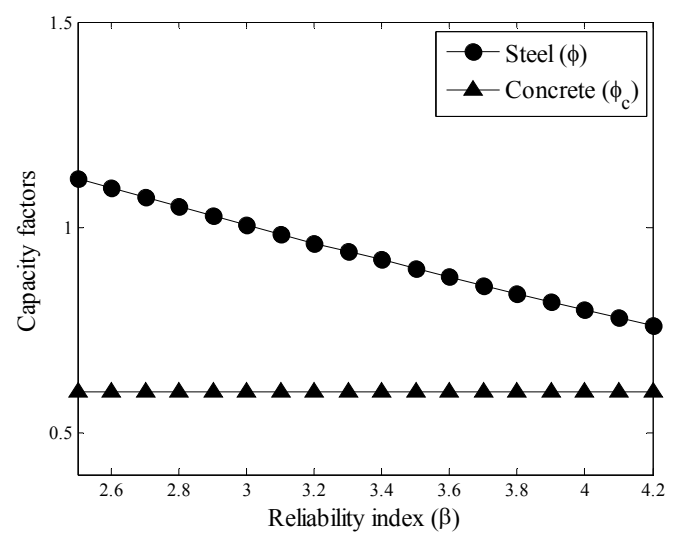

(a) Rectangular stub columns

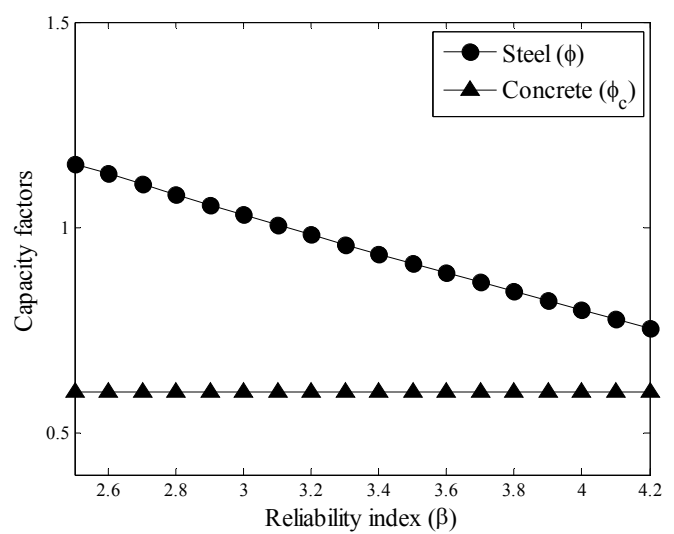

(c) Long rectangular columns

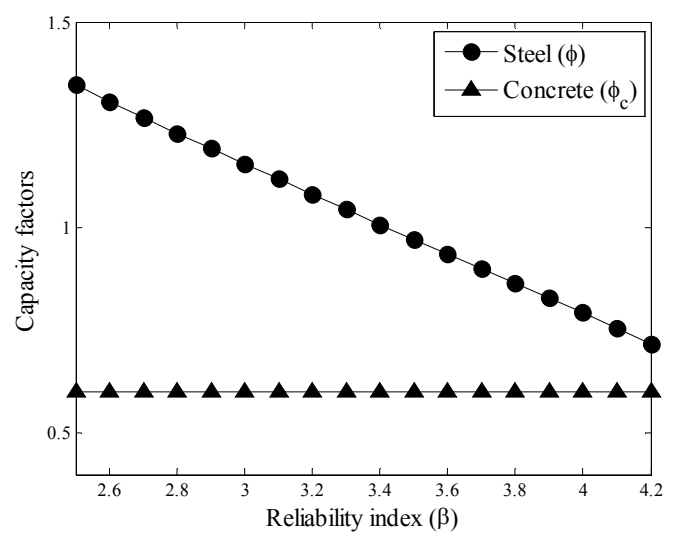

(b) Circular stub columns

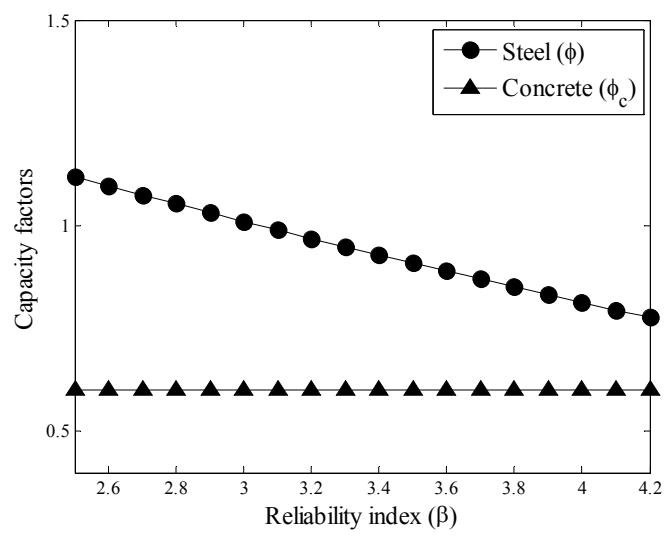

(d) Long circular columns

Figure 5. Capacity Factor Versus Reliability Index when the Capacity Factor for Concrete is Fixed at 0.6

\subsection{The Effect of Multiple Unbalanced Capacity Factors}

Johnson and Huang's method [16] and the inverse analyses in the previous sections assumed that the modelling and parameter uncertainties were same before and after the application of the capacity factors. However, they did not consider any additional uncertainties created after applying the capacity factors to the theoretical equations. In the original form of a theoretical equation, no capacity factors are considered, or it is assumed that all the capacity factors are equal to unity, and all the modelling and parameter uncertainties are estimated based on this form. However, if we apply different capacity factor values to different materials in a composite member, this will create an imbalance between the predicted strengths of these materials. This imbalance will create additional uncertainties because it will change the design equations' accuracies and propagate parameter uncertainties in a different manner. Therefore, in this study, we repeat the inverse analysis carried out in the previous section by recalculating the parameter and modelling uncertainties after applying the capacity factors. Because the application of imbalanced capacity factors for steel and concrete strengths will change the accuracy of the design equations, the uncertainties need to be updated accordingly. 


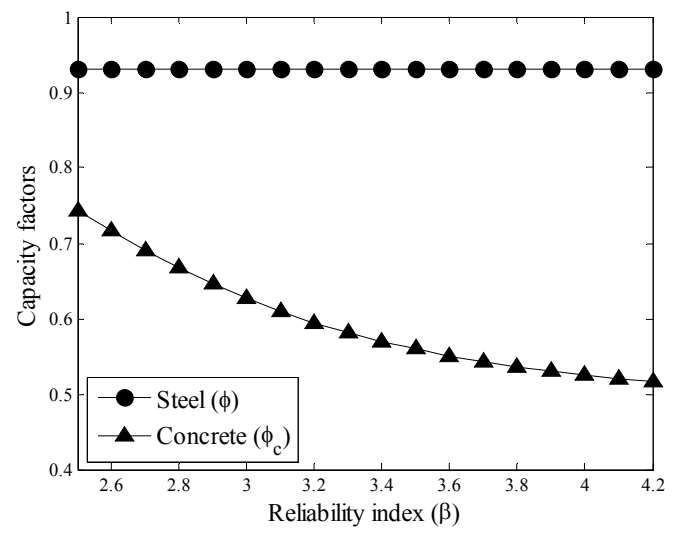

(a) Rectangular stub columns

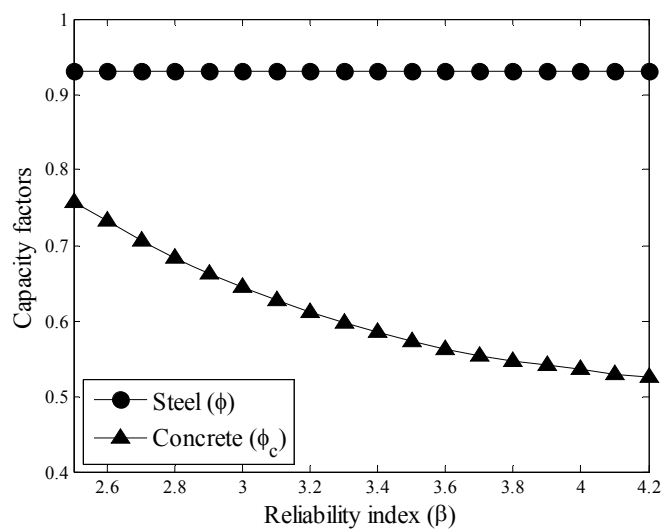

(c) Long rectangular columns

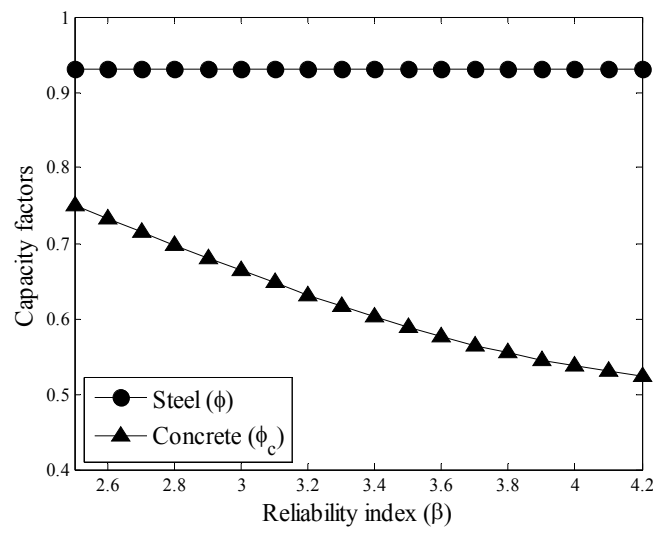

(b) Circular stub columns

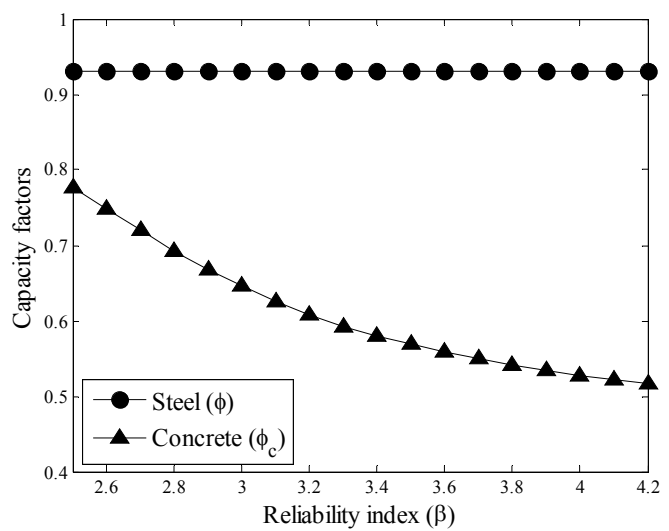

(d) Long circular columns

Figure 6. Capacity Factor Versus Reliability Index when the Capacity Factor for Steel is Fixed to be 0.93

To investigate the effect of these additional uncertainties created via the application of different capacity factors for different materials, the inverse analysis proposed in Section 5 has been repeated, but the resistance function $g_{R}(\mathbf{x})$ in Eqs. 7-10 have been replaced by $g_{R}(\mathbf{x}, \Theta)$, where $\mathbf{x}=$ the mean-measured input parameter values and $\Theta=$ the applied capacity factors. Due to this change, the values of $\bar{b}$ in Eq. 7 and $V_{r}$ in Eq. 10 are updated as shown in Table 5. In this table, the constant bias term $\bar{b}$ refers to the updated conservatism of a design equation, and $V_{r}$ (mean) refers to the updated accuracy of a design equation. For all section/member types, the $\bar{b}$ values are greater than those in the previous inverse analysis because the design equations now have more conservatism after applying capacity factors. The $V_{r}$ (mean) values are increased or remain the same after applying the capacity factors, because the accuracy of the imbalanced equations has been changed due to the application of these factors.

After applying the capacity factors provided by AS 5100, the reliabilities for all section/member types have been reduced to values close to the target reliability index, $\beta=3.04$, except for the equations for circular stub columns (Table 6). This exception occurred because the $V_{r}$ (mean) value for the equations for circular stub columns did not increase after applying the capacity factors provided by AS 5100, while the $V_{r}$ (mean) values for the other cases were increased. The increase 
in the $V_{r}$ (mean) values indicates an increase of modelling error or a decrease of accuracy, and this reduces the reliability of equations. The application of different constant values to the steel and concrete strength predictions in an unbalanced manner decreases the accuracy of the equations, except for those related to circular stub columns. It is also noted that the application of the capacity factors obtained from the Johnson and Huang's method decreases the accuracy of the equations for long circular columns and these values cannot achieve the target reliability index, $\beta=3.04$, after considering the increased uncertainties caused by the application of the capacity factors obtained from Johnson and Huang's method. The reliability indices after applying the capacity factors are also represented as a bar graph in Figure 7.

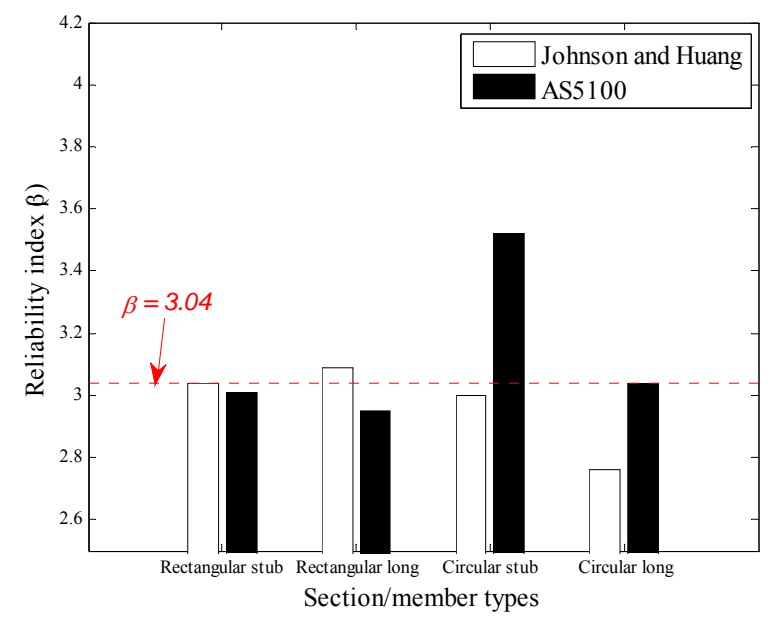

Figure 7. Comparison of Reliability Indices for Different Capacity Factors after applying Capacity Factors

It is observed that the capacity factors for composite columns in AS 5100 yield almost the same target reliability suggested in AS 5104: 2005 [26] /ISO 2394:1998 [27] after considering the additional uncertainties created via the application of the capacity factors. These results show that the current capacity factor values in AS 5100 for CFST columns need to be maintained. However, this is due to the significant reduction in the accuracy of the design equations that reduce the large conservatism embedded in these factors, which concludes that these factors are not optimally calibrated for cost-safety balanced design. In addition, the results in this paper and the parameter distributions shown in Figure 1 demonstrate that the existing design equations can be safely extended to cover a wider scope than is currently considered in either EC 4 or AISC, as follows:

- Rectangular hollow sections

o $200 \mathrm{MPa}<f_{\text {ym }}<460 \mathrm{MPa}$

o $20 \mathrm{MPa}<f_{\mathrm{cm}}<100 \mathrm{MPa}$

o Depth $h$ to width $B$ ratio of the composite cross section $1.0<h / D<2.0$

o $\operatorname{Max} h / \mathrm{t}=125 \sqrt{\frac{250}{f_{y}}}$

- Circular hollow sections

o $180 \mathrm{MPa}<f_{\text {ym }}<680 \mathrm{MPa}$

o $20 \mathrm{MPa}<f_{\mathrm{cm}}<100 \mathrm{MPa}$

o $\operatorname{Max} D / \mathrm{t}=225\left(\frac{250}{f_{y}}\right)$ 


\section{CONCLUSIONS}

The aim of this paper was to attempt to improve the practical applications of CFST members by re-calibrating the capacity reduction factors in AS 5100 [3] and investigate the effect of these factors and the factors given by AS 5100. The factor calibration method developed by Johnson and Huang [16] was used to re-calibrate the capacity factors for CFST columns in AS 5100, based on the extensive database developed by Tao et al. [7], which contains 1,583 test results for CFST columns. In addition, an inverse analysis procedure based on Johnson and Huang's method was proposed in order to estimate the reliability of design equations with known capacity factors. Using these methods, first, the capacity factors for CFST columns in AS 5100 were calibrated, and the results showed that the values of the capacity reduction factors are closer to each other than those in AS 5100. Second, the proposed inverse analysis procedure was used to estimate the reliability of the equations in AS 5100, and the results showed that the current capacity factors given in AS 5100 provide more conservatism, represented by a higher reliability than the target reliability suggested in AS 5104: 2005 [26] /ISO 2394:1998 [27]. Lastly, the inverse analysis was repeated considering the additional uncertainties created from the application of the capacity factors. It was observed that the application of different constant values to the steel and concrete strength predictions in an unbalanced manner decreases the accuracy of the equations in most cases, and the capacity factors for composite columns in AS 5100 give almost the same target reliability as that suggested in AS 5104: 2005 [26] /ISO 2394:1998 [27]. After taking all the results into consideration, the current capacity factor values in AS 5100 for CFST columns are adequate with regards to safety and can be maintained to meet the target reliability suggested in the current design codes. However, it should also be noted that this is due to the significant reduction in the accuracy of the design equations that reduce the large conservatism embedded in these factors, which leads to the conclusion that they are not optimal for cost-safety balanced design. For future research, further development of the capacity factor calibration method would be advantageous in order to incorporate the uncertainties caused by the imbalance between the predicted strengths of these materials as observed from the analysis of the proposed inverse method for estimating the reliability of capacity prediction models. It should also be noted that although these studies have been carried out for the purposes of the Australian Standards, they have important ramifications for international codes of practice regarding structural composite members such as with EC 4 [4], AISC [5], and the code of practice in Hong Kong [6].

\section{ACKNOWLEDGMENTS}

This work is supported by the Australian Research Council (ARC) under its Discovery project (Project No: DP120101944). The authors wish to thank Dr Douglas Goode, the University of Manchester, UK, and Professor Roberto T Leon, Virginia Tech, USA for providing the initial column databases.

\section{REFERENCES}

[1] Shams, M. and Saadeghvaziri, M.A., "State of the Art of Concrete-filled Steel Tubular Columns", ACI Structural Journal, 1997, Vol. 94, No.5, pp. 558-571.

[2] Chitawadagi, M.V., Narasimhan, M.C. and Kulkarni, S., "Axial Capacity of Rectangular Concrete-filled Steel Tube Columns-DOE Approach", Construction and Building Materials, 2010, Vol. 24, No. 4, pp. 585-595.

[3] Standards Australia International Ltd., "AS 5100.6:2004 Bridge Design, Part 6: Steel and Composite Construction”, New South Wales, Australia, 2004. 
[4] British Standards Institution, "BS EN 1994-1-1:2005 Eurocode 4: Design of Composite Steel and Concrete Structures", Part 1-1. London, UK, 2005.

[5] American Institute of Steel Construction, "Specification for Structural Steel Buildings. ANSI/AISC 360-10", Chicago, IL, USA, 2010.

[6] Buildings Department of Hong Kong, "Code of Practice for Structural Use of Steel", Buildings Department, the HKSAR Government. Hong Kong, 2005.

[7] Tao, Z., Uy, B., Han, L.H. and He, S.H., "Design of Concrete-filled Steel Tubular Members According to the Australian Standard AS 5100 Model and Calibration”, Australian Journal of Structural Engineering, 2008, Vol. 8, No. 3, pp. 197-214.

[8] Goode, C.D., "A Review and Analysis of over One Thousand Tests on Concrete Filled Steel Tube Columns", Proceedings of 8th International Conference on Steel-Concrete Composite and Hybrid Structures, Harbin, China, 2006, August 12-15.

[9] Wu, F.Y., "Compressive Behaviour of Recycled Concrete-filled Steel Tubes", Masters Thesis, College of Civil Engineering, Fuzhou University, China, 2006. (in Chinese).

[10] Gupta, P.K., Sarda, S.M. and Kumar, M.S., "Experimental and Computational Study of Concrete Filled Steel Tubular Columns under Axial Loads", Journal of Constructional Steel Research, 2007, Vol. 63, No. 2, pp. 182-193.

[11] Lue, D.M., Liu, J.L. and Yen, T., "Experimental Study on Rectangular CFT Columns with High-Strength Concrete", Journal of Constructional Steel Research, 2007, Vol. 63, No. 1, pp. 37-44.

[12] Tao, Z., Han, L.H. and Wang, D.Y., "Experimental Behaviour of Concrete-filled Stiffened Thin-walled Steel Tubular Columns", Thin-Walled Structures, 2007, Vol. 45, No. 5, pp. 517-527.

[13] Yu, Z.W., Ding, F.X. and Cai, C.S., "Experimental Behavior of Circular Concrete-filled Steel Tube Stub Columns", Journal of Constructional Steel Research, 2007, Vol. 63, No. 2, pp. 165-174.

[14] Yang, Y.F. and Han, L.H., "Concrete Filled Steel Tube (CFST) Columns Subjected to Concentrically Partial Compression”, Thin-Walled Structures, 2012, Vol. 50, No. 1, pp. 147-156.

[15] Chang, X., Fu, L., Zhao, H.B. and Zhang, Y.B., "Behaviors of Axially Loaded Circular Concrete-filled Steel Tube (CFT) Stub Columns with Notch in Steel Tubes", Thin-Walled Structures, 2013, Vol. 73, pp. 273-280.

[16] Johnson, R.P. and Huang D., "Statistical Calibration of Safety Factors for Encased Composite Columns", Composite Construction in Steel and Concrete III, ASCE, New York, 1997, pp. 380-391.

[17] Yu, Q., Tao, Z. and Wu, Y.X., "Experimental Behaviour of High Performance Concrete-filled Steel Tubular Columns", Thin-Walled Structures, 2008, Vol. 46, No. 4, pp. 362-370.

[18] Chen, Z., Zhu, J. and Wu, P., "High Strength Concrete and its Application", Beiing, China, Tsinghua University Press, 1996. (in Chinese).

[19] Gulvanesian, H. and Holicky, M., "Annex C - Calibration Proceedure”, Leondardo DaVinci Pilot Project CZ/02/B/F/PP-134007, Handbook 2-Reliability Backgrounds, 2005.

[20] Ang, A.H.S. and Tang, W.H., "Probability Concepts in Engineering: Emphasis on Applications to Civil and Environmental Engineering", New York, John Wiley \& Sons, 2007.

[21] Joint Committee on Structural Safety, JCSS Probabilistic Model Code, http://www.jcss.byg.dtu.dk/, 2001.

[22] Standards Australia International Ltd., "AS 3600:2009 Concrete Structures", New South Wales, Australia, 2009.

[23] Standards New Zealand, "NZS 3104: 2003 Specification for Concrete Production", Wellington, New Zealand, 2003. 
[24] Standards Australia/Standards New Zealand, "AS/NZS 1163:2009 Cold-Formed Structural Steel Hollow Sections", Sydney, Australia, 2009.

[25] Kang, W.H., Uy, B., Tao, Z. and Hicks, S., "Statistical Safety Factor Calibration of Short Concrete-filled Steel Tubular Columns", Proceedings of the 22nd Australasian Conference on the Mechanics of Structures and Materials, ACMSM 22, Sydney, Australia, 2012, December 11-14.

[26] Standards Australia International Ltd., “AS 5104: 2005 General Principles on Reliability for Structures", New South Wales, Australia, 2005.

[27] International Organization for Standardization, "ISO 2394:1998 General Principals on Reliability for Structures”, Geneva, 1998.

[28] Standards Australia International Ltd., "AS/NZS 1170.0: 2002 Structural Design Actions General Principles", New South Wales, Australia, 2002.

[29] Nocedal, J and Wright, S., "Numerical Optimization. 2nd ed.", Berlin, New York: Springer-Verlag, 2006, ISBN 978-0-387-30303-1. 